\title{
La gestión del conocimiento en las empresas de servicios de Medellín
}
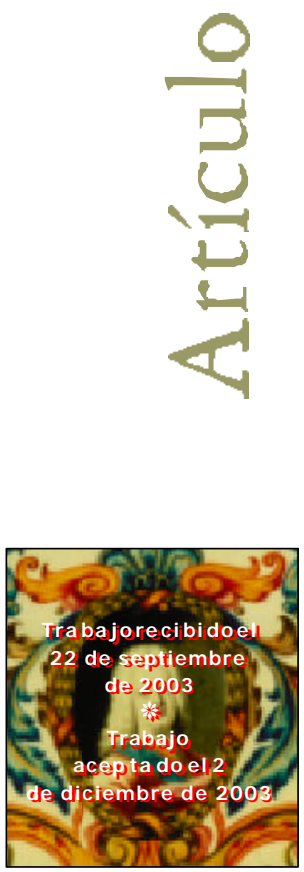

\author{
MARÍATERESAMÚ NE RATORRES \\ E-mail:mmunera@nutabe.udea.edu.co \\ AdrianaMe JíaCORREA \\ E-mail:admjia@nutabe.udea.edu.co \\ JosÉ GREgORIO Fran COGÓMEZ \\ ARILOG RE GINAPABón ANGEL \\ OSCAR O RTE GALOBO
}

Escuela Interamericana de BibliotecologíadelaUniversidad

de Antioquia, Colombia

\section{RESUMEN}

En el pre sen te ar tícu lo se des cribe la for ma en la cual se de sa rro llóla in ves tiga ción so brela "In ciden cia dela ges tión del co no ci mien to en las em pre sas de servicios Medellín entre 1995 y 2001", teniendo como base la definición de un mo delo de ges tión del conocimien to con forma do porlas he rra mien tas de ladocumentación, la terminología,lanormalización,lagestióntecnológicay elaprendizajeorganizacional, as pectosquecontribuyenala op timizacióndel capi tal in te lec tual de una orga niza ción y por tan to tienen in ci den cia en el mejo ramien to delos procesos den tro del hacerco tidiano delasins titu ciones. Se quiere además despertar la conciencia de la importancia que tiene la gestión del conocimientoen las empresas y el papel dinámico que desempeña el bibliotecólogo en los procesos de gestión del conocimiento.

Pa la bras cla ve: Gestión de la información; Gestores de información.

\section{KNOWLEDGE MANAGE MENTINTHE SER VI CES INDUSTRY OF MEDELLIN}

\author{
MARÍA TERE SAMÚNERA-TORRES \\ ADRIANA MEJÍA-CORREA \\ JOSÉ GREGORIO FRANCO-GÓMEZ \\ ARI LOGRE GINAPABÓN-ANGEL
}

\section{ABST RACT}

The paper describes the development of research on the "Influence of knowledge management in the services enterprises of Medellin between 1995 and 2001". Its ba sis was a model of knowl edge man age ment com pris ing docur mentation, terminology, standardization, technological management and organizational learning tools. These aspects contribute to the optimization of 
the intellectual capital of any organization and therefore influence the bet tering of the daily pro cesses of in sti tu tions. The aim of this pa per is to increase awareness of the importance knowledge management has for thein dus try, and the dy namic role the li brarian plays in these pro cesses.

Keywords: Information Management; Information Ma na gers.

\section{INTRODUCCIÓN}

T a gestión del conocimiento(GC) es un tópico que se ha venido introduciendo

paulatinamente en la sociedad globalizada del mundo de hoy y consiste, según los ex pertos, en op ti mizarparasu be ne ficio el ca pi tal in telec tual de las orga nizaciones. Se gún la ten den cia del grupo In te lect de Es pa ña, la GC se po dría de fi nir en forma con cre ta comola ca pa cidad que tiene todains ti tu ción de ge ne rarvalor con base en elco nocimien to que po see. Estanovedo sapers pec tiva in troduce nuevas formas de producción que trascienden las dinámicas económicas tradicionales y muestran nuevos modelos de trabajo, los cuales sefun da mentanen el servi cio comopro duc to clave de las empresas del siglo XXI.

Anteestarealidadlos pro fe sionales delain forma ciónyladocumentaciónno puedenmarginarsesino, porelcontrario, interactuarconlasnuevasdinámicasdetrabajo con el cono cimien to y comolíde resjalona dores delos nuevos proce sos de GC y gene ración deinnova ciónque con tribuyen ala evolu ciónyelcrecimien to delasins tituciones. En este orden de ideas, la Escuela Interamericana de Bibliotecología de la Universidadde Antio quia apoyólarealiza ción delainves tiga ción sobrelaincidencia delages tión del conocimien to en algu nas delas em pre sas deserviciosmás re conoci dasdelaCiudaddeMedellín.

A con ti nua ción se des cribela forma en la que se de sa rrolló esta in ves tiga ción, cuyo prin cipal fin fue ex plorarel es ta do en el cual se en con traba elde sa rrollo delaGC en diferentes proce sos que selleva ran a caboenla tipología deem pre sas señala da an te riormente.Advertimosqueeles tu diorealiza do partió dela siguien tehipótesis:eldesarrollodeprocesosde GCseencuentraenunestadoincipienteenlas empresasanalizadas.

Parain da garel es ta do de la ges tión del co no ci mien to en las em pre sas que fue ron partedelamuestrasedeterminaron cincoherramientas demedicióndelaGC:

1. EL APRENDIZAJE ORGANIZACIONAL: Entendido como la capacidad de acción de las empresas para transferir el conocimiento individual de los miembros que conformanlaorganización, alconocimien to corporativo, buscandoconello garantizar la eficiencia, eficacia y efectividad empresariales.

2. LA NORMALIZACIÓN: Proceso me dian teel cual sere gulan, co or dinan yes tandarizanlasactividadesdesempeñadas pororganizaciones públicasyprivadascon el fin de sim pli ficar proce sos, re du circos tos y tiem po, y con servarun nivel mí nimo de calidad. 
3. LA DOCUMENTACIÓN: Definida como aquella ciencia interdisciplinaria que inves tiga elcomporta mien to delain formación, las fuerzas que go biernansu utili za cióny las téc nicas de proce sa mien to delain forma ción que permiten suaccesi bilidad óptima.

4. LA GESTIÓNTECNOLÓGICA: Pro ce so de adop ción y eje cu ción de de cisio nes sobre las políticas, estrategias, planes y acciones relacionadas con la creación difusión y uso de la tecnología en una organización.

5. LATERMINOLOGÍA:De finida como la dis cipli na que se en car ga del es tu dio de los términos y los conceptos en el ámbito de los lenguajes especializados.

Alserlages tióndel conocimientouna nuevatendenciaempresarial, cen tradaenla valoracióny elusoade cua dos delos cono cimien tos que poseenlosindividuosquese desempeñanen toda organizacióny delcapital in telectual que elloin volucra,pre cisa ini ciar con una eta pa ex plo ra to ria so brela im ple men ta ción de los pro ce sos de la GC enlasdiferentesempresasdelaciudaddeMedellín.

Paraini ciareste procesodesen sibiliza ción se quiso realizarunes tu dioex ploratoriosobrelaincidencia es pe cíficadelaGCen el de sarrollo delas empre sas de servicios de la Ciu dad de Me de llín. Se eligió esta cla se de em pre sas por que en ellas se de sa rrollan actividades estrechamente relacionadas con los proce sos de GC, como el intercambio de información, la comunicación especializada,la utilizacióndeterminologíaespecíficanormalizadayladocumentacióndeprocesos, entreotros.

Se acla ra ade más que al serun es tu dioinicial sus re sul ta dos revela rán el es ta do en el que se encuentra la aplicación de las herramientas de GC. No obstante se pretende crearlane ce si dady la mo tiva ción paraim plemen tarrutinas que con duz can a con siderar la GC como as pec to funda men tal den trodelos pla nes y pro yec tos de cre cimien to delaempresa,tantoenelnivelnacionalcomoenelinternacional.

Además esin dispensableque en elambien te empresarialse empiecea es timularla cultura en las organizaciones que aprenden, del aprovechamiento de los conocimien tos con los que cuen ta el per so nal ex perto, asícomo es timularla utiliza ción, el aprovechamien toyla aplicaciónygeneración de conocimien toquepermitenlainnovacióny,porende, lageneración denuevosproductosyservicios.

Porelloes ne cesario analizarlasaccionesquesiguenlasempresasparaaprovechar losrecursos dein formacióny, enefecto, elconocimien to como ca pi tal in tan gible de toda orga niza ción, el cual se aplica y se trans fie reme dian te el nuevoacon te cimien to so cial:"la sociedad del co no cimiento".SegúnFrancis co Aguade roF., este acon te ci mien to hacambia dolas bases materiales denuestrasvidasyel pa noramaeconómico delmundo,asícomocondicionadoyreo rientadoelfuturodelaspersonas, eltrabajo, lasinterrelacionesyhastaladistracciónydiversión.

El mun do de la co mu nica ción, en su acep ción más am plia, es el prin cipal vec tor eco nó mi co en la era de laglo ba liza ción; el tra ba jo ma nuales sus ti tuido por el trabajo intelectual emanado de la información y el conocimiento. Consecuentemente estamos ante una economía en la que la productividad y la competitividadestán en función más de la aplicación 
es tra té gicadecono cimien tos delain formación,los procesos de ges tióny marketing que de factores tradicionales como el capital, grandes industrias y maquinarias y la fuerza de trabajo mecánica, podemos entonces decir que ésta es la eradelainfomacónydl conoimiento ${ }^{1}$

Ensín te sis, lainves tiga ción so bre la in ciden cia delaGC en las em pre sas de servicios de la Ciu dad de Me de llín servi rá como pun to de par tida para ini ciar una se rie de actividades tendientes a fomentar una nueva cultura empresarial apoyada en una efec tiva ges tión delos da tos, la in forma cióny el conocimien to po seído porlasorga ni za cio nes. Esta nue va cul tu ra se preo cu pa por las men tes de quie nes, de una u otra forma, pue denproyec tarsus conocimien tos hacialains titu ciónala que sirven, yasu vez, por que és tas pue dan re tri buir y es ti mu lar el apor te que ge ne ran. Ade más es indispensableresaltar el pa pelque jue ga el bi blio te có lo go en el uso y la ge ne ra ciónde conocimien to en las em pre sas, como pro mo tor de nuevos apor tes que re dunden en el au men to de la in no va ción y ge ne ra ción de nue vos pro duc tos y, por ende, de nuevasgananciasparalasorganizaciones.

\section{OBJE TIVOSDE LAIN VESTIGACIÓN Objetivo general}

Evaluar la incidencia que han tenido los procesos de Gestión del Conocimiento enalgunasdelasempresasdeMedellínentre1995y2001.

0 bjetivos específicos

Determinarlosindicadores que midenlos proce sos deges tión delconocimien to para quelasempresaslosapliqueny consecuentementeim plementenlasherramientasestandarizadasoriginadasporlainvestigación.

Suge rirlas herramien tas que em pleala GCparafortalecerlacompetitividaddelas empresasmedellinensesenelmercadoglobal.

Identificarlas for tale zasy debilida desquepresen tanlasem pre sas dela Ciu dad de Medellín en relación con la utilización de las herramientas del conocimiento en los procesos, estrategiasyprocedimientos,paraoptimizarlasactividadescorporativas.

\section{EST RATE GIA METODOLÓGICA}

Paraalcanzaralos obje tivos plan tea dos eneste es tudioy te nien do encuentala revisión dela li te ra tu ra exis ten te so bre ges tión del cono cimien to, se de termi nóqueel estudio encajabaenlacatego ría deestudioexplora torio, pueseldesa rrollodelate má tica es muy reciente y el análisis so bre su aplica ción en las em pre sas de la Ciu dad de Medellínnosehabíaabordadoantes.

1 Francisco Aguadero Fernández, La søiedad dela infommaión / Francisco Aguadero Fernandez. Ma drid: Acen to, 1997.-p. 16. 
El diseño de investigación seleccionado fue de corte no experimental. La intención fue ob ser varel es ta do de al gu nas va ria bles en el cam po de la ges tión del co no cimiento, yanalizarloscambiosocurridosentreelperiodo 1995-2001.

Con base en la información asimiladasobre los diferen tes proce sos delages tión del conocimiento en el ámbito universal, se quiso hacer una ex plo ra ción en las empresas de servicios dela Ciu dad de Me dellíneiden ti ficarla forma enla que sees taban mani festan does tos proce sos en ellas. Se de terminó quelas empresas de servicios se ajus tan a crite rios es tre cha men te rela cio na dos con la GC, ya que mu chos delos produc tos de esas em pre sas son de ca rác ter in tan gible, y ade más, que esas em pre sas tienenalainformacióncomoprincipalmateriaprima.

Deestamanerase eligió, a través de un mues treo no probabilís tico, a las empresas: ISA, EPM, SURAMERICANA, ICPC, FENALCO yCONCONCRETO.

\section{Modelo para medir la incidencia de la gestión del conocimiento en empresas de servicios}

Comoresultadodelestudiodetalladosobre diferentesmodelosdegestióndelconocimien toqueutilizan aquellasempresasquedeseangenerarventajascompetitivas sos tenibles en el tiempo, el equi po de inves tiga ción origi nó un mo delo para me dirla gestióndelconocimientoenlasempresasdeMedellín.

Paraellose de terminóquelas herramien tas claves quepermiten evaluarlos procesos de ges tión de co no ci mien to son las siguien tes: la do cu men ta ción, la ter mino logía,la normaliza ción, el apren dizajeorganizacionalylages tióntecnológica. Se eligieron estas herramientas porque permiten explicar el por qué de la posición privilegiada de algunas empresas. El gáfico1 ilustra el modelo para me dirlages tión delconocimientoenlasempresasdeservicios.

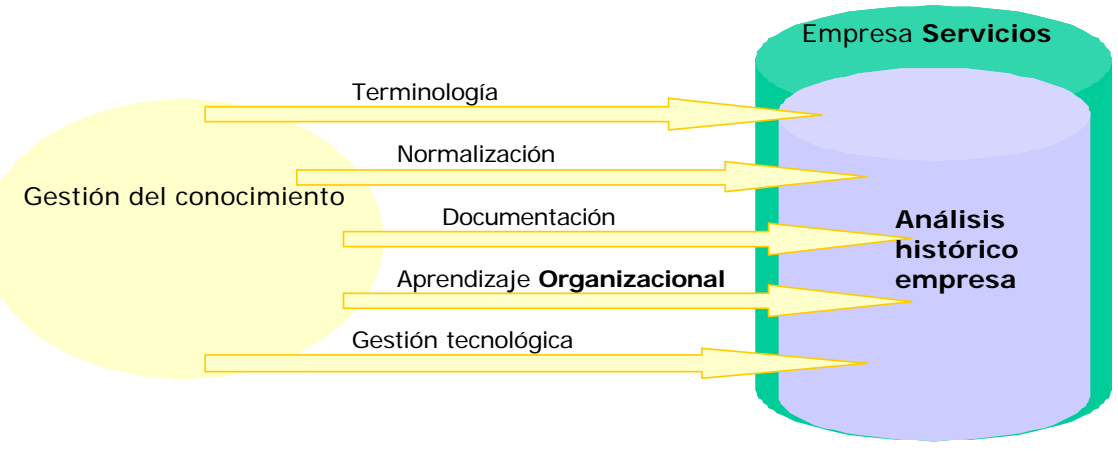

Gráfico No. 1. Modelo Propuesto 


\section{InvestigacónBiblicteedógia v. 17 No. 35 julio/ diciembre de 2003}

En rela ción con elAPRENDIZAJEORGANIZACIONAL se puede observar una interesanterelaciónen treestaherramientayla GC, pues a tra vés de ella la em pre sa extien de suca pa cidad de ac ción a partirdela trans fe ren cia delos co no cimien tosin dividualeshacialosconocimientosorganizacionales.

Eles tudiointen taiden ti fi carlas vías o me dios que utilizanlas empre sas ob je to de lamues tra,para convertirelconocimiento in dividualen conocimien toorganizativo, para lo cual se toman como actividades clave del aprendizaje organizacional, la comunicación organizacional, la capacitación institucional, los procesos internos, la comunica ción en treclien tes y em plea dos, y el pa pel queen esto de sem peña elpro fesionaldelainformación.

En lo referentea comu nicaciónorganizacio nal, lainves tiga ción rela cionalossiste mas que le apor tanideas a la em pre sa: ban co de ideas de los clien tes, ban co deideas delos empleados, ylosmeca nis mosutilizados para compartirelcapitalintelectualrevertidos en experienciascompartidas a través de diferentes medios: vía intranet, en reunionesyenexperienciasdocumentadas.

En lo correspondiente a la actividad capacitación institucional se busca analizar las di fe ren tes ac cio nes quelle van a cabolas em pre sas para de sa rrollaral per so nalen el campo profesionalypersonal.Laaplicacióndelaprendizajeorganizacionaltiene una rela ción di rec ta con la ca pa ci ta ción delperso nal.Laca pa cita ción per mi tequeel talen to huma no mo difiquesus comporta mientos yde sa rrolleo ad quiera nuevas formas deac tua ción con la in ten ción de in cre men tarla ca pa cidad de to marde cisiones y accionesefectivas.

Laactividadcapacitacióninstitucional es la variablequepresentamayornúmero deres pues tas porpartedelas di feren tes empre sas ana lizadas. Elanálisis de comportamiento de esta actividad con base en el cuestionario es ascendente en el periodo analizado,yconbaseenlosindicadoreselcomportamien to observadoesvariable.S e po dría pen sarquelos de parta men tos de ges tión hu ma na de al gu nas delas em pre sas analizadasestán bien estructurados e in clu yen me ca nis mos en sis te mas de in forma ción para regis trarcadauna delasacciones realizadasensusáreas.

Enlapartealusivaalaactividadprocesosinternos (procesos de generacióndein formacióninterna), sedeterminala con tribucióndelasideas generadas porlos em pleados en la creación, mejo ramien to o complemen to de nue vos procesos, productos o servi cios, y el im pac to que és tos han tenidoen el crecimien to dela orga niza ción. Lain formación so breprocesosin ternos su minis tra da porlas em presas, presenta elmenornú meroderegis trosencadaperiodoyuncomporta mientova riablesegún elcuestionario ylosindicadores.

Paralaco munica ción en tre clien tes yem plea dos el me canis mo dein te rac ciónutiliza do en los ele men tos que com po nen esta ac tividad es la co la bo ra ción no for malizada, entendida como la información aportada por los proveedores, los clientes y otrosagentes externosalainstitución.

En cuan to a la NORMALIZACIÓN: se parte dela de fini ción quele da elIns ti tu to ColombianodeNormas'Técnicas, ICONTEC, aquella: 
Actividad que consiste en establecer, con respecto a problemas reales o potenciales, disposicionesparausocomúnyrepetido,encaminadosallogro del grado óptimo del orden en un contexto dado. ${ }^{2}$

La normalización sería entonces aquel proceso mediante el cual la organización bus ca rála op timiza ción que ade más ga ran ticela eficien cia enla rea liza ción delosproce sos, la for ma en la cual se pue da ob te neruna ma yorga nan cia (gra cias a la ca li dad de los pro duc tos que se ori gi nen) y los re sul ta dos que se al can cen con base en su apli cación. En formapa ralelase debees ta ble cerla cul tu ra dela do cu men ta ción y el apren dizajecontinuos, locualgarantizaráeladecuadoyexcelentedesempeñoeneltiempo.

Sise apre cia a la ges tión del co no cimien to comola ca pa ci dad que tienen las or ga nizaciones para ge ne rar va lor con base en el co no ci mien to, se ob serva que exis ten muchos as pec tos en co mún conla normalización. Dehe cho es preciso se ñalarque siuna organización, notieneestablecidospatrones denormalizaciónydedocumentación de procesos, conmirasalaob ten cióndecalidad, resul tarámuycomplicadoiniciarunaimplementación de rutinas de GC que faciliten el aprendizaje continuo, la optimización delcapitalin telectualylagene racióndenuevoconocimien to,y tambiénsecomplicará lainnovacióny,porsupuesto,laobtencióndemayoresutilidadesparalaorganización.

En cuanto a la DOCUMENTACIÓN ésta se interrelaciona estrechamente con la gestión del conocimiento desde diferentes ámbitos y ambas se complementanpara garantizar una efectiva gestión del capital intelectual y de los activos intangibles de unaempresa. Como prime ramedida es im portantere sal tarque todo proce so degestión del conocimiento debe originar una infraestructura que optimice la diseminación de lain for ma ción yla ex pe rien cia asi mila da enla laborprofe sional de to doslos miembros de una en ti dad. Para ello es ne ce sa rio con tarcon fuen tes que re co pi len y documenten el conocimien to explícitodela empresa, que cons tituyanunamemoria corporativadelamisma.

Tam bién de ben exis tir di rec to rios de expertos en las áreas quelein te re san ala empresa,paraqueéstospue danserconsultadosoportunayrápidamenteenelmomento en el que selos ne ce site. Igual men te se re quie re con tar con fuen tes ex ternas que den cuen ta dela si tua ción delmerca do, la ac tividaddelos compe tido res, ylain for mación rela tiva a los clien tes tan to po ten cia les como rea les. Y como com plemen to delo anterior se debe contar con una relación de competencias que permitateneraccesoal conjunto de conocimientos reque ridosparadesarrollarunalabores pe cíficadentro delorganigramadelaorganización.

El papel del documentalista es fundamental en estos procesos, pues es él quien debe es ti mu lar la di ná mi ca de los miem bros de la ins ti tu ción en el sen ti do de do cumentareficientementelosproce sos que sede sarrollancomotales, yjalonareltrabajo en equipo. Igual men tedebeserélquien analice, al maceney difunda elconocimien to recopiladoenlainstitución.

2 ICONTEC. Normalización [documento electrónico]. Bogotá: Icon tec, 2003. http://www.icontec.org.co/normalización.asp/ [consulta mar 24 2003] 


\section{Investigacón Biblictecoógia v. 17 N o. 35 julio/ diciembre de 2003}

En re su mi das cuen tas se pue de ex presarque den tro delain te rrela ción que exis te entre los procesos de gestión del conocimiento y documentación, esta última juega unpapelpreponderantecomoárea que ga rantiza el accesoalosdocumen tos necesa riosyalos conocimien tos queserequie ran parasa tis facerlas diversasnecesidades de in formacióngenera das en dife rentes frentes delasins titu ciones, yproducirelmejoramientofuturodelaactividad,proyecciónyconsolidacióndeéstas. ${ }^{3}$

En cuan to a la GESTIÓN TECNOLÓGICA: es importan te señalarque tan toésta comolages tión del conocimien to son ac tivida des que se com plemen tan paraalcanzar un obje tivo co mún. Si se dota a una orga ni za ción con to dos los equi pos tec no ló gicosparasumodernizaciónesnecesarialacapacitación delpersonal,yaquelosequipossolos, sinlaoperación del pro fe sionalidóneo, noservirán de nada para op timizar losprocesosylaeficienciadelaempresa.

Mientras la gestión tecnológica sirve como herramienta que propicia el mejor desempeño de los procesos de una institución en poco tiempo, la gestión del conocimien to es timulapro ce sos deapren diza jecontinuo en to dos ycadauno delos procedimientos que se realizan en una organización, lo cual por supuesto va a redundar en obteneravancesconstantes enlas diferentesoperacionesyprocesosqueprecisamente incluyenlastécnicasdegestióntecnológicaylasactividadesdeinnovaciónydesarrollo.

En cuan to a laTERMINOLOGÍA. Sise con cibelages tión delconocimien to como aquellaestrategiamediantelacualsevalenlasempresasparamejoraprovechartodos los co no cimien tos que ellas ge ne ren, utilicenytrans mi tan paraop timizarsupro ducción, en ton cesla terminología en tra ráa for marparte en esteproce sodecreación, utiliza cióny trans mi sión de co no ci mien tos, pues pue delle gara ejerceruna es pecialincidencia en el mejoramientode los procesos de comunicación y en los procesos de creación de nuevas denominaciones para la nueva producción que se realice, así como en la sis te ma ti za ción de los tér mi nos y con cep tos que se em pleen en to das las actividadesempresariales.

El conocimiento y su gestión son, hoy en día, el medio a través del cual crece la compe titividad empresarial, tanimportan teparahacerprogresarla empresaylograr así que las ideas, las perso nas y la tec no lo gía sean ca pa ces de in ven tary ges tio nar sistemaseficientesquepermitanlatransmisión,eldesarrolloylainnovacióncontinua.

\section{Génesis del modelo}

Este es tu dio lo componen ocho eta pas que dan cuen ta delproce solle va do a cabo paraconstruirelmodelopropuestoparalasempresasestudiadas.

La etapainicial del es tu dio nace de la ne cesi dad de ana lizarlos di versos esta dios delas em presas de servicios des delaimplan ta ción delas di fe rentes fa ses de la GC hasta el estado actual en que se encuentran los recursos y las capacidades de la organización.

3 Ma ría TeresaMú ne ra To rres.Lagestióndlconodimientoysurelaciónconladbamentación/ Ma ría Te re sa Múnera Torres y Arilog Regina Pabón Angel. - Medellín. - Vol. 25, no. 2 (jul-dic 2002) ; p. 36. 
* La segundaetapa buscaiden ti ficarlasherra mientasprincipales dela GC: la documentación, la terminología, la normalización, el aprendizaje organizacional y la gestión tecnológica

* La terceraetapa con sis te en com pa rar las he rra mien tas de GC conlas ac tivida des pro pias delas em pre sa de servicios, paraiden ti fi carpara cada he rra mienta su papel clave en el proceso de gestión del conocimiento.

* En lacuarta etapa se con si de raun con jun to de ac tivida des por herra mienta, con el fin de hacer un diagnóstico del estado de éstas en las organizaciones.

* La quinta etapa consiste en elaborar indicadores de valor cuantitativo y cualita tivo parame dirlain ciden cia delas he rra mien tas en la em presa. Se trata de expresar el estado, la productividad y eficiencia de los procesos, entre otros aspectos.

* La Sexta etapa consiste en evaluar y validar el instrumento de medición a partir de la prueba piloto.

* En la Séptima etapa, de recolección de la información, intervienen tanto las fuentes primarias como las secundarias.

* En la etapa octava, de medición y evaluación, se presentan los resultados obtenidos paracada una delas herra mien tas a par tirdelos cuadros-re su men decomportamien tos de tectados enlasem presasconbaseen elcues tionario $\mathrm{y}$ los indicadores.

A continuación se detalla el gráfico que representa las etapas componentes del modelo.

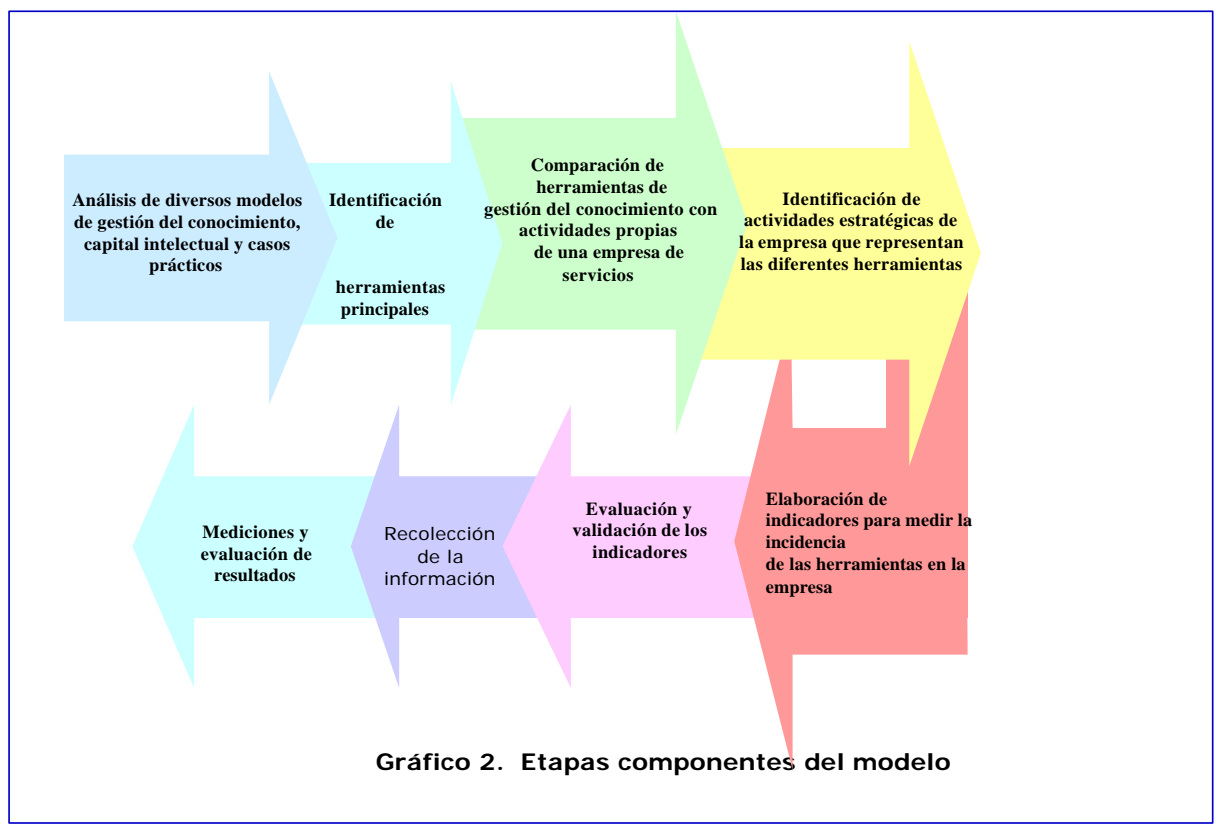




\section{InvestigacónBiblicteedógia v. 17 No. 35 julio/ diciembre de 2003}

\section{Prueba Piloto}

Con el fin de va li dar y revi sar la ca li dad y per ti nen cia de las pre gun tas delcues tionarioantes dereprodu cirlodefinitivamente, seproce dearealizarunapruebapiloto. Para ello se aplica elins tru men to en una em pre sa conca rac te rís ticas simila res alas de lasempresasqueconformanlamuestra.

La prue ba pi lo to se lle vó a cabo en la em pre sa INTEGRAL S.A, que ofre ce servicios deconsul to ría eningeniería.La empre sa aplicó elins tru men to, sin muchoéxito, pordificultades ajenas al instrumento. Al termi narel plazo fija do parala aplica ción delapruebapilo to,la empresaemi tió un concep to favorablealins trumen toyafirmó queésteesaplicable,sinningunamodificación, alasempresasobjetodela muestra.

\section{Recolección de datos}

Los da tos se re colec tan en un solo mo men to y en un tiem poúnico, con el pro pó sito de describir las va ria bles y ana lizarsuin ci den cia en el de sa rro llo de las em pre sas. Para ello se define un cuestionario compuesto por cinco herramientas: aprendizaje organizacional,documentación, terminología, normalizaciónyges tióntecnológica, las cuales son el fun da men to para di señarel mo delo pro pues to de me di ción para la GCenlas empresas.

De igual manera se definen unos indicadores que sirven de pauta a las empresas para po der evaluarel es ta do de de sa rro llo de las he rra mien tas es truc tu ra das en esta investigación. Ver tabla 1, con algunos de los indicadores definidos para la herramientadocumentación.

Tabla 1

Ejemplo cuadrodeindicadores dedocumentación

\section{INFORMACIÓN SOBRE DOCUMENTACIÓN}

Objetivo:determinar el es ta do de las ac tivida des do cu men tales en la em pre sa como herra mien tas delages tión del co no cimien to

Actividad: organización de la documentación en la empresa

Nú me ro de uni da des de in for ma ción exis ten tes en la em pre sa (biblio te cas, cen tros de documentación, archivos, ban cos de da tos, cen tros de orien ta ción y re fe ren cia les).

Nú me ro de per so nas que es tán a car go de las uni da des de in for ma ción / Nú me ro to tal de empleados. 
Tabla 1 (Cont.)

Ejemplocuadroindicadoresdedocumentación

\begin{tabular}{|c|}
\hline $\begin{array}{l}\text { Actividad: adquisición de } \\
\text { fuentes primarias }\end{array}$ \\
\hline $\begin{array}{l}\text { Nú me rode libros elec trónicos ad qui ridos anual mente / To talde fuentes ad quiridas } \\
\text { anualmente. }\end{array}$ \\
\hline $\begin{array}{l}\text { Nú me ro de re vis tas elec trónicas ad qui ri das anual men te / Nú me ro de fuen tes ad qui ridas } \\
\text { anualmente. }\end{array}$ \\
\hline Númerodenormas ad quiridas anual mente / nú me ro de fuen tes ad qui ridas anual mente. \\
\hline Actividad: adquisición de fuentes secundarias \\
\hline Númerode fuen tes se cun da rias ad qui ridas anual men te enla empresa. \\
\hline $\begin{array}{l}\text { Núme rodebibliogra fíasimpresas ad quiridas anual mente/ nú me ro de fuentes ad qui ri- } \\
\text { dasanual mente. }\end{array}$ \\
\hline $\begin{array}{l}\text { Nú me ro de bibliogra fías elec trónicas ad qui ri das anual mente / nú me ro de fuen tes ad qui- } \\
\text { ridas anualmente. }\end{array}$ \\
\hline
\end{tabular}

Si se observa en la Tabla 1 una de las actividades, por ejemplo, "Adquisición de fuentes se cun da rias", a esta ac tividadle co rres pon de unin dica dor que da cuen ta sobre elgra do de participa ción que tienenlas fuen tes se cun da rias en el to talde ad quisicionesdedocumentosquerealiceunaempresaanualmente.

El cuestionario se en tre ga a cada una de las em pre sas que con for man la mues tra, acom pa ña do de unins truc tivo yunglo sa rio, con el finde ase gu rarquelas pregun tas delcues tiona rioseentiendanconcla ridad. Observarlas tablas $2 \mathrm{y} 3$.

ElnumeralI delins trumen toincluye una se rie depregun tas dein formacióngeneralacercadela em presa. En elins trumen to completo, los numerales II, III, IV, V y VI, in clu yen, para cada una delas he rra mien tas de ges tión del co no ci mien to tra baja das en este es tu dio, una se rie de preguntas agru padas porac tivida des. La presen tein forma ción está es crita en for ma de re su men, por lo cual las pre gun tas no son in clui das y sóloseincluyenlosnombresdelasactividadesquesonobjetodediagnóstico. 
Tabla 2

Resumen de la guía para recolecntar información Estructura del instrumento

\begin{tabular}{|c|}
\hline I. INFORMACIÓN INSTITUCIONAL \\
\hline Nombre o razónsocial: \\
\hline Fe cha de ini cia ción de la em pre sa: \\
\hline ObjetoSocial: \\
\hline Información general \\
\hline Nú me ro de em plea dos y tra baja do res que la bo ran en esta em presa \\
\hline Númerodepersonaladministrativo \\
\hline $\begin{array}{l}\text { Nú me ro de em plea dos y tra ba ja do res que tie nen con tra to a tér mi no in- } \\
\text { definido }\end{array}$ \\
\hline Núme ro to tal de clien tes de la em presa \\
\hline Núme ro to tal de ser vi cios que ofre ce la em presa \\
\hline Núme ro to tal de pro ce sos que ma neja la em presa \\
\hline Número to tal de pro duc tos que ofre ce la em pre sa \\
\hline Númerototaldeservicioscontratados \\
\hline Presupuesto anual de ventasproyectado \\
\hline Presupuesto anual asignadoparalacapacitación \\
\hline Presupuesto asignadoparainves tiga ciónydesarrollo \\
\hline Valorejecutadoencapacitación \\
\hline Valorejecu tadoeninves tiga cióny de sarrollo \\
\hline Ren dimien to neto to tal de la em presa \\
\hline Ren di mien to neto to tal de los ac ti vos de la em presa \\
\hline Valor pro me dio de las ven tas \\
\hline
\end{tabular}

\section{AN ÁLISIS DE LA INFORMACIÓN}

Para rea lizarel análisis dela in for ma ción su mi nis tra da porlas em pre sas que conformaron la mues tra, se proce dió a rea lizarunos grá ficos de com por ta mien tos, me dian telos cuales se ex pre san las ten den cias de cada em pre sa en los as pec tos rela cionados a cada una de las herramientas. A continuación se ilustra un ejemplo del análisis delaherramienta-documentaciónenunadelas empresasmuestra.

Con base en la información aportada por cada gráfico, se pudieron establecer com porta mien tos y con clu sio nes para cadauna delashe rra mientas encues tión. Por tan to seilus traa con tinua ción el resul ta do delanáli sis de cada una delas he rramientas tenidasencuentaenelmodelopropuestoenlainvestigación. 
Tabla 3

So bre las He rra mien tas de la ges tión del co no cimien to

\section{INFORMACIÓN SOBRE APRENDIZAJ E ORGANIZACIONAL}

Objetivo: Identificar los ade lan tos al can za dos por la em pre sa en cuan to al flu jo de infor ma ción, el ca pi tal in te lec tual y los pro ce sos de sa rro lla dos a tra vés del ta len tohu ma no de la organización

\section{Actividades de aprendizaje organizacional}

Comunicaciónorganizacional

Capacitacióninstitucional

Procesos internos

Comunica ción en tre clien tes y / o empleados

\section{INFORMACIÓN SOBRE DOCUMENTACIÓN}

Objetivo: de ter mi nar el es ta do de las ac tivi da des do cu men ta les en la em pre sa como herra mien tas de la ges tión del co no cimien to

\section{Actividades de documentación}

Organiza ción de la do cu men ta ción en la empresa

Adquisición de fuen tes primarias

Adquisicióndefuentes secundarias

Análisisdedocumentos

Implementacióndeservicios y consultas documentales

Implementacióndeservicios y consultas documentales

Inversiónendocumentación

\section{INFORMACIÓN SOBRE GESTIÓN TECNOLÓGICA}

Objetivo: obtener una visióngeneral so bre as pec tos relevan tes dela ges tión tec noló gica y elcapital tec noló gicoen la em presa

\section{Actividades de gestión tecnológica}

Esfuerzoeninnovación

Comprade tec nología

Propiedadintelectualdisponible

Do ta ción de tec no lo gías delain forma ción y de tele co mu nicaciones

Do ta ción de tec no lo gías de la pro duc ción

Innovacióntecnológica

Propiedadintelectualconseguidainternamente

Ventade tec nología 
Ta bla 3 (cont.)

Sobre las Herramientas de la gestión delconocimiento

\begin{tabular}{|c|}
\hline V. INFORMACIÓN SOBRE NORMAUZACIÓN \\
\hline O bjetivo: eva luar el gra do de apli ca ción de la nor ma li za ción en la em pre sa \\
\hline Actividades de normalización \\
\hline Implementación denormasin ternasyex ternas \\
\hline Realizacióndecapacitaciónennormalización \\
\hline Normalizaciónde procesos \\
\hline Inversiónennormalización \\
\hline VI. INFORMACIÓN SOBRE TERMINOLOGÍA \\
\hline $\begin{array}{l}\text { O bjetivo: de ter mi nar en qué me di da la em pre sa tie ne co no ci mien to y aplica la ter mi no- } \\
\text { logía como herra mien ta dela ges tión del co no ci mien to }\end{array}$ \\
\hline Actividades de terminología \\
\hline Actividadterminológica \\
\hline Trabajoterminológico \\
\hline Precisiónterminológica \\
\hline Elaboracióndetraducciones \\
\hline Elaboracióndesistemas deconceptos \\
\hline Recursosterminológicos \\
\hline Publicaciones \\
\hline Personal capacita doypersonal de apoyo \\
\hline Capacitaciónenterminología \\
\hline Capacitaciónen traducción \\
\hline Con tra ta ción de servicios de tra duc cióny terminología \\
\hline Realiza ción de proyec tos de in ves tiga ción en ter mino lo gíay tra duc ción \\
\hline Presupues to asigna do ala bo res de termino logíay traducción \\
\hline
\end{tabular}




\section{Tabla 4}

Resumendecompor ta mien tosgene rales de tec ta dos en las em presascon base en la herramienta documentación

\section{Empresa: 1}

\section{Herramienta: Documentación}

\begin{tabular}{|c|c|c|}
\hline \multicolumn{3}{|c|}{ Cuestionario } \\
\hline ACTIVIDAD & & COMPORTAMIENTO \\
\hline \multirow[t]{3}{*}{$\begin{array}{l}\text { 1.Unidades de informaciónexis } \\
\text { tentesen la em presa }\end{array}$} & 11 & $\begin{array}{l}\text { Entre } 1997 \text { y } 2001 \text {, se pue de apre ciar que ha exis ti do una } \\
\text { biblio te ca. Se pue de apre ciarun com porta mien to es ta ble } \\
\text { en este as pec to. }\end{array}$ \\
\hline & 1.3 & $\begin{array}{l}\text { Entre } 1995 \text { y 2001, se apre cia que han exis ti do } 5 \text { ar chi vos. } \\
\text { Tam bién se pue de ver un com por ta mien to es ta ble. }\end{array}$ \\
\hline & 1.4 & $\begin{array}{l}\text { Entre } 1995 \text { y } 2001 \text {, se apre cia que ha exis ti do una base de } \\
\text { datos. Seobservaun comportamien toes ta ble. }\end{array}$ \\
\hline \multirow[t]{2}{*}{$\begin{array}{l}\text { 2. Perso nas a cargo de las uni da- } \\
\text { desdeinformación }\end{array}$} & 2.1 & $\begin{array}{l}\text { Se pue de ob ser var que en tre } 1997 \text { y } 2001 \text {, con ta ron con } \\
\text { unbibliotecólogo.Comportamiento estable. }\end{array}$ \\
\hline & 2.2 & $\begin{array}{l}\text { Aun cuan do en tre } 1995 \text { y } 1999 \text {, se con ta ron } 12 \text { per so nas } \\
\text { que da ban apo yo, a par tir del año } 2000 \text { se re du jo este nú- } \\
\text { mero a } 8 \text { personas. }\end{array}$ \\
\hline 3.Fuentesprimariasadquiridas & 3 & $\begin{array}{l}\text { Se tie ne in for ma ción sólo del año 2001. No se tuvo en } \\
\text { cuen ta para el análi sis de com por ta mien to }\end{array}$ \\
\hline \multirow[t]{3}{*}{ 5.Análisisdedocumentos } & 5.1 & $\begin{array}{l}\text { Alcon si de rar el com por ta mien to en el aná li sis de do cur } \\
\text { men tos, se pue de ob ser var lo si guien te: En 1997 se ana li- } \\
\text { za ron } 551 \text { li bros im pre sos, 1998:621; 1999: 319; 2000:268; } \\
\text { 2001:241. Se apre cia un com por ta mien to de des cen so en } \\
\text { el análisis. }\end{array}$ \\
\hline & 5.2 & $\begin{array}{l}\text { El aná li sis de li bros elec tró ni cos mues tra el si guien te com- } \\
\text { por ta mien to: } 1997: 1058 ; 1998: 231 ; 1999: 15 ; 2000: 30 ; \\
\text { 2001:31. Se apre cia va ria ción en el com por ta mien to y se } \\
\text { nota ma yor ten den cia a la dis mi nu ción del aná li sis. }\end{array}$ \\
\hline & $\begin{array}{l}5.3 \\
\uparrow \downarrow \uparrow\end{array}$ & $\begin{array}{l}\text { El análi sis de re vis tas im pre sas in di ca el siguien te com por } \\
\text { tamiento: 1997: 28; 1998:38; 1999:70; 2000:30; 2001: } 31 \text {. } \\
\text { Se apre cia tam bién va ria ción, con la di fe ren cia de que la } \\
\text { ten den cia que más se pue de no tar es un au men to en el } \\
\text { análisis. }\end{array}$ \\
\hline 6. Servi cios que se ofre cen & 6.1 & $\begin{array}{l}\text { La bi blio te ca ha ofre ci do en tre } 1997 \text { y } 2001,3 \text { ser vi cios. } \\
\text { Tendenciaes tabledecomportamiento }\end{array}$ \\
\hline
\end{tabular}


Tabla 4 (Cont.)

Resumen de comportamientos generales detec tados en las empresascon base en la herramienta documentación

\begin{tabular}{|c|c|c|}
\hline \multicolumn{3}{|c|}{ Empresa: 1} \\
\hline \multicolumn{3}{|c|}{ Herramienta: Documentación } \\
\hline \multicolumn{3}{|c|}{ Cuestionario } \\
\hline \multirow[t]{3}{*}{ ACTIVIDAD } & & COMPORTAMIENTO \\
\hline & $\begin{array}{r}6.3 \\
\uparrow \\
\end{array}$ & $\begin{array}{l}\text { En el ar chi vo se ob serva que ini cial men te en tre } 1995 \text { y } \\
1998 \text {, se pres ta ban } 3 \text { ser vi cios. A par tir de } 1999 \text { el nú me ro } \\
\text { au men tó a } 6 \text { ser vi cios. Ten den cia de au men to a par tir de } \\
1999 \text {. }\end{array}$ \\
\hline & $\begin{array}{l}6.4 \\
--\end{array}$ & $\begin{array}{l}\text { Los ser vi cios que se ofre cen en los Ban cos de da tos pre- } \\
\text { sen tan una ten den cia es ta ble. En tre } 1995 \text { y } 2001 \text { se ofre- } \\
\text { cieron } 3 \text { servicios. }\end{array}$ \\
\hline $\begin{array}{l}\text { 15. Presupuesto asignadoaunida } \\
\text { desdeinformación }\end{array}$ & $\begin{array}{r}15.4 \\
\uparrow\end{array}$ & $\begin{array}{l}\text { En el pre su pues to asig na do a los ban cos de da tos de la } \\
\text { em pre sa se pue de ob servar un com por ta mien to de aut } \\
\text { men to, a par tir de } 1998 \text {. En tre } 1995 \text { y } 1997 \text { se con tó } \\
\text { anualmente con } 3 \text { mi llo nes, y a par tir de } 1997 \text { se au men tó } \\
\text { a } 4 \text {. }\end{array}$ \\
\hline $\begin{array}{l}\text { 16. Presupuesto ejecutadoenuni } \\
\text { dadesdeinformación }\end{array}$ & 16.4 & $\begin{array}{l}\text { Con re la ción a la eje cu ción pre su pues tal se des ta ca tam- } \\
\text { bién la eje cu ción pre su pues tal en los ban cos de da tos y la } \\
\text { mis ma ten den cia de au men to que en el pre su pues to asig- } \\
\text { nado. }\end{array}$ \\
\hline \multirow[t]{2}{*}{$\begin{array}{l}\text { 17. Co mi tés de apo yo a las uni da } \\
\text { desdeinformación }\end{array}$} & $\begin{array}{l}17.1 \\
-- \\
\end{array}$ & $\begin{array}{l}\text { En cuan to a los co mi tés de apo yo que han exis ti do en la } \\
\text { bi blio te ca se apre cia una ten den cia es ta ble des de el año en } \\
\text { el cual se ini cia; es de cir, } 2 \text { co mi tés en tre } 1997 \text { y } 2001 \text {. }\end{array}$ \\
\hline & $\begin{array}{l}17.4 \\
--\end{array}$ & $\begin{array}{l}\text { La ten den cia ob ser va da en re la ción con los co mi tés de } \\
\text { apo yo del ban co de da tos fue es ta ble en tre } 1997 \text { y 2001: } \\
\text { tres co mi tés por año. }\end{array}$ \\
\hline \multirow[t]{2}{*}{$\begin{array}{l}\text { 18. Número de perso nas que han } \\
\text { conformadoloscomitésdeapoyo }\end{array}$} & $\begin{array}{l}18.1 \\
--\end{array}$ & $\begin{array}{l}\text { En la bi blio te ca han sido } 4 \text { los miem bros que han con for- } \\
\text { ma do el co mi té de apo yo cada año, en tre } 1997 \text { y } 2001 . \\
\text { Tendencia estable. }\end{array}$ \\
\hline & $\begin{array}{l}18.2 \\
--\end{array}$ & $\begin{array}{l}\text { En el cen tro de do cu men ta ción han sido } 3 \text { las per so nas } \\
\text { que con for ma ron el Co mi té de Apo yo a di cho cen tro en } \\
\text { tre } 1997 \text { y } 2001 \text {. Se apre cia una ten den cia es ta ble. }\end{array}$ \\
\hline
\end{tabular}




\section{Análisis por herramientas}

A nálisis de la herramienta aprendizaje organizacional

Puedeobservarse, en términos generales, que la actividad comunicaciónorganiza cio nal con res pec to al cues tio na rio (tablas 2 y 3), mues tra un com por ta mien to variable; es decir, sepre sentaines ta bilidad enelperiodoanalizado(1995-2001), con aumen tos y dis mi nu cio nes de un año a otro. Elanáli sis de esta ac tividad con base en los in dica dores es difícilde precisar, ya queno se dis pu sodein for ma ción su ficien te para es table cerlas relaciones; sinembargo, una delas empresas suminis tró similituden el comportamientocon base enlosindica dores yen el com porta mien to que seanalizó conbase en elcuestio nario, por tan to seob servó un compor ta mien to va ria bleenamboscasos.

Lain forma ción parcial ob teni da porparte delas empresas nopermi te rea lizarun análi sis muy obje tivo; sinem bargo, podría pen sarse quela fal ta de re gis tros so brelos sis te mas de apor tes deideas, in tercam bio de ex pe rien cias de los em pleados víain tranet, re unio nes, etcé te ra, se debe a la fal ta de con cien cia delas or ga niza cio nes em presariales sobre la necesidad de establecer mecanismos y sistemas informáticos que permitanalmacenaryrecuperarelconocimientoqueellasgeneran.

Laactividad“comunicación entre clien tes yemplea dos”también presentauncomporta mien to va riable tanto en elanálisis delcues tiona riocomoeneldein dica dores. La poca información entregada por las empresas al respecto podría hacer pen sar que en estas organizaciones aún no han consolidado lo suficiente las redes de colaboración en tre sus agen tes clave: clien tes ousua rios y sus emplea dos. Las orga niza ciones de ben reflexionar so brelaim por tan cia de res pon dera sus clien tes ousua rios de una ma ne ra eficiente y eficaz, para crearverda de ras es truc tu ras so cia les y de este modo me jo rarel desarrolloorganizacional.

Se gún lain forma ción pro por cio na da porlas seis em pre sas obje to dela mues tray con base en el cues tio na rio y losin dica do res, és tas se pue den cla si ficaren cuan to ala importanciaqueseleprestaalaherramientaaprendizajeorganizacional,así:

\begin{tabular}{|l|l|l|l|l|l|}
\hline 1.Empresa4 & 2.Empresa1 & 3. Empresa3 & 4.Empresa5 & 5.Empresa2 & 6.Empresa6 \\
\hline
\end{tabular}

A nálisis de la herramienta documentación

Alrealizarelanálisis decomportamien tos delaherramien tadocu mentaciónenlas empresas que conformaron la muestra para la investigación, y con base en las respues tas brin da das al cues tio na rio y los in di ca do res de fi ni dos para el mis mo, se puedenestablecerlas siguientesapreciaciones:

Las empresas de servicios de la Ciudad de Medellín que conforman la muestra para la investigación cuentan en su gran mayoría con unidades de información que apoyan y respaldan los procesos de aprendizaje, investigación, documentación y proyec ción de di chas uni da des a nivel in terno, ex terno, in terno yex terno, o in terno exclusivamente. 


\section{InvestigacoónBiblictecoógia v. 17 N o. 35 julio/ diciembre de 2003}

En su gran mayoría las empresas cuentan con personal idóneo y capacitado al fren te de las uni da des de in forma ción, y tam bién con per so nal de apo yo que con tribu ye con las di fe ren tes ac tivida des que ahíse de sa rro llan. No obs tan te se pu die ron observar comportamientos de descenso en este aspecto, sobre todo en los últimos años. Ade más, frente al núme ro to tal de em plea dos, el porcentajedelpersonal delas unidadesdeinformaciónerasumamentereducido.

Alexa minarlaim portan cia que sele daalaad qui sición de fuen tes dein for ma ción en las em pre sas, se pudo es ta ble cerque las fuen tes que tie nen un ma yor gra do de adquisición son las fuentesprimarias, en es peciallos do cu men tos y revis tasimpresos, asícomolasnormas.

Conrelaciónalaad qui sición de fuentes se cun da riasse pue de señalarque estetipo de fuen tes no es muy utiliza do en es tas em pre sas, por lo que su gra do de ad qui si ción es muy re du ci da. Sin em bar go, se des ta ca el he cho de que una de las em pre sas síadqui rió este tipo de ma te ria les du ran te el pe rio do de fi nido parala mues tra y que tuvo un comportamiento variable en un 39\% anual en las adquisiciones de índices, y un com portamien to de au men to del $3,3 \%$ anual en la ad qui si ción de guías, di rec to rios, catálogosyotros.

Considerandolaorganiza cióndelain formaciónenlasseisempresasqueconforma ron la mues tra, re sal ta el he cho de que aun cuan do en to das se rea liza esta la bor, ésta se cen tra en su ma yor parte en do cu men tos y re vis tas im pre sos. Cabe re sal tar que en las empresas dondeseregis tra ronlos archivoscomounida des dein formación, el nú mero dedocumen tosanalizadosenelarchivoresul tósersuperioralnúmerodedocumentos analizadosenlasbiblio te caso centros de documenta ción. Tambiénsepuedeobservar queseinician procesos de análisis de docu mentoselectrónicos comounanuevaactivi dad de las unidades de información. En términos generales se puede afirmar que el comporta mien to que seapre cia en las em pre sas que con forma ronla mues tra con rela ción al análi sis de in for ma ción es va ria ble, y que exis tein te rés enla rea liza ción de esta actividad.

Alobservarlos servicios tra dicio nales que se ofrecen enlas uni da des de in forma ciónse pue de apre ciarquela mayo ría de las em pre sas brin dan servicios de con sul tas. No obs tan te enalgu nas sólo sere gis train forma ciónal res pec to apartirdel año 2001. Alrepa raren el tipo de servicios que se ofre cen se pue de no tarquelos ser vicios tra dicio nalesquemás se brin dan sonlos derefe renciaperso nal, a dis tan cia, dise mina ción selec tivadelain forma ción ybibliográ ficos. Noobs tan te seobservaqueen los archivoslos servicios de consultas sóloselebrin danalperso nalin ternodela em presa;por loquelosservicios de consul tas ex ternas a dis tan cia obiblio grá ficos nose dan en esta unidad dein for ma ción. Eneste aspec to el comportamientoquepredominaes estable y tie ne ten den cia a au men tar anual men te. En tér mi nos ge ne ra les y con re la ción a esta actividad, tres de las empresas mues tra manifiestan pres tacióndediferentes servicios tradicionales; las de másno regis tranin formaciónal respec too sólo señalaninformación para elaño2001. 
Porlo que toca a la aten ción y re solu ción de con sul tas en las uni da des de in for mación, se pue de apre ciar que las con sul tas in ter nas se lle van a cabo en to das las uni dades de in forma ción de las em pre sas y con un com por ta mien to va ria ble, a la vez que coincideel númerodeconsul tas rea liza das con elnúmero deconsul tas re suel tas. En cuanto a las consul tas ex ternas se ad vier te que mues tran un com porta mien tova ria ble, de acuerdo con la política y la naturaleza de la Unidad de Información.Existen unidades de in forma ción, como el ar chivo, que no atien den con sul tas ex ternas. Sin embargo se dio el caso de cen tros de do cu men ta ción yba ses de da tos que aten díanen sugranmayo ría consultas ex ternasenun númeromuyalto.

Alabor darelapoyo eco nó mi co que tienen las unida des dein forma ciónparadesa rrollarsuscoleccionessepuedeobservarlosiguiente:

Cuatrodelas em presas regis tran asignaciones pre supues tales alas unidades deinforma ción. No obs tan te en al gu nas de ellas di cha asigna ción seini cia a partirde 1999 ó 2000 y en igual medida se manifiesta la correspondiente ejecución presupuestal. Esto in di ca que en al gu nas em pre sas sólo se está con tan do con apo yo eco nó micoa partirdelosúltimosaños delperiododelamuestra.

En cuan to al apo yoins ti tu cio nal que re cibenlas uni da des dein forma ción, se puede es ta ble cer cómo en cuatro de las em pre sas exis ten Co mi tés de apo yo a las uni dadesdein formaciónquein teractúanconellasyles brindanasesoría.

Sin embargo en algunas, dichos comités surgen a partir de 1997. El número de miembros que constituyen estos Comitésoscila en tre 3 y 12 miem bros. Esto in dica que las empresas tienen interés en el papel que juegan las unidades de información den tro de sus ac ti vi da des y sus di fe ren tes pro ce sos. Pero que dan du das con las empresas que no registraron información sobre el particular, ya que aun cuando son muy re co noci das no se sabe a cien cia cier ta cómo tie nen or ga niza do este as pec to en laempresa;segúnlasrespuestasbrindadasalinstrumentodeinvestigación.

A continuación y con base en la información proporcionada y el número de respuestas re suel tas en el cues tio na rio, se pue den cla si fi carlas em pre sas fren te a la herramientadocumentacióndelasiguienteforma:

\begin{tabular}{|l|l|l|l|l|l|}
\hline 1.Empresa3 & 2.Empresa4 & 3.Empresa1 & 4.Empresa2 & 5.Empresa5 & 6.Empresa 6 \\
\hline
\end{tabular}

Siendoelporcentaje deres pues ta del $20 \%$, resul ta difícil efectuarun análisisob jetivo sobre esta herramienta en las empresas muestra. Algunos de los posibles motivos que origina ron di cha si tua ción son la fal ta de con cien cia por par te de las em pre sas que noledanimportanciaalaactividaddedocumentación den trode susprocesosproductivos; la falta de conocimiento de la importancia que tienen las fuentes secundarias comomaterialesimportantesdentrodeldesarrollodeladocumentaciónenlaempresa; yla fal ta de com pren sión, por par te de las empresas, sobre el gradodeim por tan ciaque poseenlasunidades deinformación diferentes delarchivo, comobibliotecasycentros dedocumentación, entreotros. 


\section{InvestigacónBiblicteedógia v. 17 No. 35 julio/ diciembre de 2003}

Porotraparteal realizarelanálisis res pectodelosindicadoresquese de finieron en laherramientadedocumentación, sepuedenclasificarlasempresasdeestaforma:

\begin{tabular}{|l|l|l|l|l|l|}
\hline 1.Empresa 3 & 2.Empresa4 & 3.Empresa1 & 4.Empresa2 & 5.Empresa5 & 6.Empresa6 \\
\hline
\end{tabular}

Encuan to alos in dicado res elporcen taje de res pues ta fuedel $25 \%$. Portan toen el análisisdecomportamientosresultadifícilpoderestablecerunanálisiscompleto que décuentadelestadodelaherramientadocumentaciónenlasempresasmuestra.

En términosgenerales se po dría ex pre sar que aun cuan do en las em pre sas en las quela he rramien ta dedocumenta ciónsede sarrollódeuna forma muyincipienteysin te nerel apoyo su ficiente paraimpulsarlospro cesosde ges tión del cono cimientonece sarios que es timulen lautiliza ción yge ne ra ción de conocimien to, y porendelaintroduc ción dein no va cio nes, también se pudo ob servarotras en las quela docu mentación se desarrolla de una forma más dinámica, lo cual contribuye a desarrollar procesos de uso ygeneración denuevoconocimientotan toen estasorganizaciones comoenelmedioexterno.

De todas formas aunque las empresas que con formaronla mues tra cuen tan con unidades de información, realizan actividades de adquisición y análisis de información, ofre cen los servi cios de con sul tain ternay ex terna, cuen tan con pre su pues to y comités de apoyo, care cen delas con diciones que permitan elde sarrollode procesos de gestión del conocimiento y estimulen el uso y la generación de conocimiento, o denlugarain nova cionesqueledeparen mayorva lorala organización. Noobstante, sepue de ex presarqueluego de realizarse esta ex ploración so bre elmanejoein cidencia delas herra mien tas de la ges tión del co no cimien to enlas empresas, mu chas deés tasempezaronarealizarprocesosdemejoramien toyoptimizaciónenalgunas dees tasherramientas, en estecasoenladedocumentación.

\section{A nálisis de la herramienta gestión tecnológica}

Luego de rea lizarelanálisis dela aplica ción delins trumen to dein ves tiga ción, particularmente en lo atinente a la herramienta gestión tecnológica, se pudo observar que las preguntas que estaban formuladas en este sentido no tuvieron ninguna respuesta.

Esto sepuededeberamuchosfactores, en treloscualessedestacanlossiguientes:

- La nodocumentación delos procedimientosrela cionadoscontodala ac tivi dad tecnológica que se implementa en las organizaciones.

* La no existencia de estrategias de planeación del desarrollo tecnológico en las empresas, que faciliten el trabajo armónico entre las diferentes actividades con la ayuda de la tecnología.

La po si bilidad de que exis ta un alto des per dicio de lain for ma ción y el co no cimiento generados durante los procesos productivos de las empresas, los cuales se hubieran podido utilizar con un mínimo de esfuerzo para mejorar la posición competitiva de las organizaciones. 
Se podría precisar igualmente que en las organizaciones pueden existir debilidades en cuan to a la de fi ni ción de po líti cas cla ras, y de nor mas y he rra mien tas que permitan un mejor aprovechamiento de la información que está siendogenerada día a díaenlaorganización.

Noseencontrócorrespondencia en trelos recursosinvertidosenI+Dylas respues tas a las preguntas del instrumento concernientes a la gestión tecnológica, este comportamien to puede serdebidoalas siguien tes razones. En primerlugar, a quela capacidad de gestióntecnológicadocumentada por las empresas que conformanlamues tra es baja, a pe sar de quela tec no lo gía que utilizan es mu cha y está ac tua liza da. En se gundolugar, a que el pro me dio para cada una de las ac tivida des está muy porde bajo del nivelde ad qui sición de tec no lo gías y del uso cons tan te de cada una de ellas. Esto se debe a unalto gra do deine xis ten cia y a de fi cien cias en losins tru men tos dela ges tión deinnovacióny de es tan darización delos sis temas de medición dela em presa. Entercerlugar, a quelos re sul ta dos delages tión dia ria no son ana lizados, cen tralizadosy, menos aún, di fundidos. Esto, unidoalbajo análi sis dein forma ción que se re co pila,indicaunabaja capacidaddeaprovechamientodeésta. Porúl timolasempresastampocosees fuerzan muchoencon servarlain forma ciónyestoqui zás ex plica elbajoniveldegene ración de nuevosconocimientosy,obviamente,sudifusión.

Se observóciertoénfa sisen lainnovacióndel conocimiento,pero sunivelindica queelesfuerzorespondesolamenteapresionesdelmercado.

La faltadeefectividadenlaintegra ción delas diferentes herramientas delagestión delco no cimien to en la em pre sa, y la fal ta de méto dos para ge ren ciarla tec no logía en el senodelas empresas, in dican la exis ten cia de fallas enlos me ca nis mos y ca nales relacionados con la actividad de Gestión Tecnológica, y en el propio proceso de implantacióndelagestióndelconocimientoenlasorganizaciones.

De este modo una propuesta de trabajo se centra en la necesidad de integrar de forma estratégica la Gestión Tecnológica en las empresas. Se considera necesario que paraque estapro yec ción se mate rialice, laac tividadde GT debe for mar par te activadelosprocesosdedocumentaciónynormalizacióndelaorganización.

A nálisis de la herramienta normalización

Luegodeobservarlain formaciónarrojadapor elins trumen todeinves tigacióny ana lizarlos com por ta mientos delas em presas que lo res pon die ron, se pue den ob tenerlassiguientesconsideraciones:

En tér mi nos ge ne rales, la he rra mien ta nor ma liza ción no cuen ta aún con eldesarrolloideal parain tro du cirenlasempresaslos procesos deges tióndelconocimiento. En la mayoría de las empresas es tu dia das se pudo apre ciar el es ca so tra ba jo de normalización, si tua ción que por su pues to re dun da en los bajos niveles de docu menta ción,gestióntecnológica,aprendizajeorganizacionalytrabajoterminológico, ya que precisamente la normalización contribuye enormemente a optimizar la eficiencia empresarialyelestímuloalainnovación, aspectodeterminantede GC. 


\section{InvestigacoónBiblictecoógia v. 17 N o. 35 julio/ diciembre de 2003}

Al haceruna lec tu ra delos com por tamien tos en con tra dos con relación a la he rramientanormalizaciónenlas diferentesempresases tudiadas, sepuedeprecisarentérminosgeneraleslasiguientesituación:

De las seis empresas que conforman la muestra, sólo la empresa uno se esmeró conlas pregun tas delins tru men to dein ves tigación, en la he rra mien ta denor ma liza ción.Las demásempresasnohicieronestodebidoalossiguientesmotivos:

* La depen den cia que se en car ga ba de ma nejar la norma liza ción en una delas empresas fue trasladada a la Ciudad de Bogotá y la persona que tenía el conocimiento completo de este as pec to se re ti ró dela empresa,jus to des pués de las reformas que se suscitaron en ella, hace dos años.

* En otras dos de estas em pre sas ape nas en el año 2002 se ini cia ron pro ce sos de normalización, razón por la cual no se registró ningún tipo de información en las preguntas correspondientes a esta herramienta.

* Otro fac tor quein flu yó fue el he cho de que las em pre sas fue ran tan gran des y complejas, situación que según el coordinador de agilizar el instrumento de investigación en una de las empresas muestra, fue mo tivo para no po der hacer un registro completo y específico de la información solicitada.

* Por último, una de las empresas de la muestra agilizó el instrumento de inves ti ga ción, pero no lo en tre gó, si tua ción que hizo que no se re gis tra ra ningún tipo de datos enlas he rra mien tas de fini das parala inves ti ga ción en esta empresa.

Auncuan dosepresen tólaan teriorsi tua ción esim portanteregis trarel com porta mientodelasempresasqueagilizaronelinstrumentodeinvestigación.

Con base en las respuestas suministradas por la empresa que sí agilizó la herramientadenormalización, sepuedenprecisarlassiguientesapreciaciones:

Se des ta ca elini cio dela aplica ción de pro ce sos de nor ma liza ción en la em pre sa a partir de 1997 en 13 de sus de pen den cias. A par tir de di cho año se re ci be asig na ción presupuestal anual para desarrollar esta he rramien tay seim pul sanla ad qui si ción de normasylacapacitacióndelpersonalennormalización.

También se apre cia la apli ca ción de nor mas na cio na les, en tre las cua les se des tacanlasdeseguridad, lastécnicas, lasambientalesylas decalidad.

Se resalta también la realización anual de procesos de auditoria, y la solicitud de asesorías externas que se han requerido para implementar la normalización de los procesos.

Igualmentesedestacalain troduccióndeinnovaciones documentales,enespecial lasqueproducenserviciosnuevos.

Para esta empresa la introducción de procesos de normalizaciónha sido de gran importancia, ya que conbaseenés tos hapodidodesa rrollaracciones demejoramientoeinnovación.

Al exa mi nar la in formación con base en la de fini ción delos in di cadores se pue de establecerlosiguiente: 
Segúnlain formación proporcionadayelnúme rodepreguntas res pondidas enlos indicadores, sepuedenclasificarlasempresasenloreferentealaherramien tanormalización, así:

\begin{tabular}{|l|l|l|l|l|l|}
\hline 1.Empresa1 & 2.Empresa2 & 3.Empresa5 & 4.Empresa4 & 5.Empresa3 & 6.Empresa 6 \\
\hline
\end{tabular}

Alagruparlas res pues tas de las em pre sas, se pue de ob ser varque delas cuatro ac tivida des dela herra mien ta nor ma liza ción, dos de ellas cuentan con res pues tas a al gunasdesuspreguntas:

Enva rias delas pre gun tas dela ac tividad “im plemen ta ción de nor masin ternas y ex ternas" seob tuvo res pues taporparte de dos delas empresas. Los as pectosque obtuvieron res pues ta de esta ac ti vidad, fue ron: nú me ro de nor mas que se aplican enla em presa;núme rodenormaslocales que seaplicanenla empresa;nú me ro denormas nacionales que se aplican en la empresa; número de normas internacionales que se aplican en la empresa, y nú me ro denor mas de com pe tencia la bo ral que se aplican en laempresa.

Otra delas ac tivida des que ob tu vo res pues ta porparte deuna de las em pre sas objetodelestudio fueladenominada “inversiónen normalización”, delacualseob tuvo in formación enlos siguien tes as pectos:pre supues to anualasignadoparanormaliza ción; presupuesto anual asignado para adquisición de normas; presupuesto anual asigna dopara aplicación denormas; ejecución presupuestalen normalización; ejecur ción anual en la adquisición de nor mas; presu pues to anualejecu ta do enla capacita ción en normalizacióny número de innovaciones documentadasanualmente y que producenserviciosnuevos.

Conestosresulta dos sehace difícil realizarunanáli sis obje tivo sobreelnivelen que se encuentra la aplicación de la herramienta normalización en las empresas de Medellín.Sonva rios los mo tivosque originandicha si tua ción. Unoes elhechodeque apenas seini ciaron los procesos decalidadydedocumen ta ciónd ela in for mación, asícomola incorporación de procesos de normalización en varias de las empresas que sólo le die ron agili dad al cues tiona rio has ta el año 2001. De to das for mas con esta si tua ción seconfirmala hipó te sis plan tea da enla formulación delproblema deinves tigación, en lacualse pre cisa balo in cipien te que es el de sa rro llo de pro ce sos comolanormalización, como parte de los pro ce sos de ges tión del co no ci mien to en las em pre sas de serviciosdeMedellín.

A nálisis de la herramienta terminología

Alagruparlas res pues tas delas em presas, pue de observarseque delas 13activida des de la herramienta terminología, nueve de ellas cuen tan conres pues tas a al gu nos desuscuestionamientos (Actividadterminológica,trabajoterminológico,precisión terminológica, elaboración de sistemas de conceptos, recursos terminológicos, publicaciones,personal capacitado y personal de apoyo,capacitaciónenterminología, realización de proyectos de investigación en terminología y traducción), donde se 


\section{InvestigacoónBiblictecoógia v. 17 N o. 35 julio/ diciembre de 2003}

destacanlas actividades:precisión terminológica,recursosterminológicos, publicaciones por los resultados positivos arrojados en algunas de las cuatro empresas encuestadas. No hay respuesta para cuatro actividades (elaboración de traducciones, capacitación en traducción, contratación de servicios de terminología y traducción, presupuestoasignadoalaboresdeterminologíaytraducción).

En las actividades que obtuvieron respuesta se observan en general comportamientosque fluctúanen tre "Estable"y "Variable(quecambia ovaría)".

La consulta de recursos terminológicos para resolver dudas terminológicas, es un tipo deservicio queno seofreceen to das las unida des de in forma cióntenidasencuenta paralainves tiga ción. Sin embargo, dos delas em presas regis tra ron da tos al respecto, lo cualmues tra quelos tesau ros, diccio na rios yglo sa rios es pe cializa dos son re cur sosterminológicosutilizadospararesolverdudasterminológicas, y resaltacómoenunad e las empresaselrecursoterminológicomásutilizadoeseltesauro.

A sim plevis ta,podríapen sarse que el re sul ta do dela aplicación del cues tionarioy los indicadores de terminología en las empresas fue positivo. Sin em bar go si se observancon ma yordetenimien tolas res pues tas sobreel nú mero to tal depreguntas, el resultadovaríaconsiderablemente.

Con estos resultados se hace difícil realizar un análisis objetivo sobre el nivel en que se encuentra la aplicación de la herramienta terminología en las empresas de la Ciu dad de Me dellín. En la presen ta ción de esta in ves tiga ción se plan tea ba: "El flu jo dein forma ción, lacomunica ciónespecializa da, lautilizacióndeterminologíaespecifica normalizada, la documentación de procesos y las diferentes normas, como herramientas claves del proceso de Gestión del Conocimiento, juegan un papel vital paralograreldesarrollodelasempresas. Porello, essumamenteimportante, manejar adecuadamenteestasherramientasorganizacionales, parafacilitarelintercambio internacionaldecapital tangibleein tangible, yaque enlame didaqueseestableceun canalde co munica ción, se docu men tanlosproce sos yse aprove chalain for ma ciónyla ex pe rien cia de una com pañía, se lo gra una ma yor sa tis fac ción de los clien tes o usua rios y se responde rápidamente a las condiciones cambiantes del mercado. Sin embargo, a pe sar del pa pel tan im portan te que jue gan las he rra mien tas de la ges tión del conocimien to eneldesarrolloorganizacionaldelaempresa, seobservaqueaúnnos e hanincorporadoen suto talidadenlaculturaempresa rialcolombiana.Estasituación lleva aque sepresenten de ficiencias enlos proce sos deproduccióny enla debidaproyecciónalexterior".

La investigación muestra que, en general, las empresas poseen un "valor consciente" muy bajo y un "valor in cons cien te" muy alto dela ter mi no lo gía, pues por el tipo de actividades de las empresas encuestadas, resulta evidente que manejan un gran flu jo de in for ma ción y ter mi no lo gía. Para ci tar sólo un caso, por cada ser vi cio que cadaunadelasem presas encuesta das ofrezca, existe un concep to quelaempresa tieneclaramente delimita doy precisado. Estoes terminologíay esto muestraquesin unaterminología delimita day precisanosería po siblela comunica ciónyportan to no sepodrían ofrecerlosservicios. 
En este sen tido se con clu ye en ton ces quelas em pre sas aplican la he rramien ta terminologíapara elbuendesempeñodesusdiferentesac tividades, loquesucedeesque no sa ben que lo ha cen. Esto quie re de cirque la ter mi no lo gía como he rra mien ta de la ges tióndelconocimien to seaplicademane raincipiente, in conscienteyparcialenl as empresas de la mues tra. Re sul taim por tan te que las em pre sas se cons cien ticen dela relevancia de la terminología y el valor que ésta tiene en la comunicación monolingüe,bilingüeyplurilingüe.

Esindudablelaimportan ciaque de sempeña elmanejoeficien te delaterminología dentro de la em presa, comovehículo con duc torde unaade cuada co munica cióndentrodelos diferen tes procesos que se de sarrollan den troy fue ra de ella. Enla em pre sa se interrelacionan una serie de sectores caracterizadosporunmanejo terminológico específico.Sepuedeobservarcómodentrodeunamismains titución selogranen contrar varios grupos: el grupo de los profesionales expertos monolingües, empleados bilingües, obre ros ypersonal de apo yo. Cada uno de es tos grupos ma ne ja una termi nología específica que los di fe rencia de los de más. Si se cuen ta con una ade cua da sis te ma tizaciónde di chasterminologías, sepuede fundamentarunsis tema decomunicación que oriente los diferentes procesos de in tercambiodein forma ción en trelos diversosgrupos de la empresa. En los países europeos por ejemplo, se ha iniciado la creación de bancos de datos terminológicos, en los cuales está sistematizada toda la terminología que se emplea enlas empre sas, locual facili ta la co mu nica ción en trelosin dividuos que las conforman y, por ende, los procesos que se desempeñan entre ellos. $\mathrm{Al}$ respecto HeribertPichtilustralosiguiente:

No cabe duda, la em pre sa es uno delos pro duc to res y con su mido res más importantes de terminologías. És tas, a su vezen tran comocons titu yen te en la comunicacióninterna y externa de la empresa. Así, la terminología es una herramienta en el conjunto del proceso productivo y debe considerarse como factor de producción 'sui generis'. Producir y vender un producto sin documentación es impensable; hoy día, la documentación for ma par te in te gran te del pro duc to, y en mu chos sec to res de servicio y consul ta,ladocumentación mis marepresenta el producto.Deahísepue dededucirque eldes cuido dela terminología equivale auna dis minu ción a priori del producto. ${ }^{4}$

Siseconcibelages tión delconocimiento comoaquellaes tra tegiamediantela cual se valen las empresas para aprovechar mejor todos los conocimientosque se generen, utiliceny transmitan en ellasparaop ti mizarsu producción, en tonces laterminología en tra ráa for mar par te en este pro ce so de crea ción, utilizacióny trans mi sión de conocimien tos, ya que, comos eexpresóanteriormente,laterminologíapue dellegara ejercerunaes pecialincidencia en elmejoramien to delos procesosdecomunicación y en los pro ce sos de crea ción de nue vas de no mina ciones para la nueva produc ción que

4 Picht,Heribert. “Terminología parala empresaylain dus tria”/ He ribertPicht. // En: Tercersimpo siolberoamericanadeTeminologa,Ritem Terminologíay De sa rrollo/UniónLa tina.-Buenos Aires, 1994. p. 91-97. 


\section{InvestigacoónBiblictecoógia v. 17 N o. 35 julio/ diciembre de 2003}

se rea lice, así como la sis te ma tiza ción de to dos los tér minos y con cep tos que se empleendurantetodaslasactividadesempresariales. ${ }^{5}$

Según lain formación proporciona day el nú me rode pregun tas res pondidas en el cues tionario, sepue den clasi ficarlas empre sas enloreferenteala herramientaterminología,así:

\begin{tabular}{|l|l|l|l|l|l|}
\hline 1.Empresa 2 & 2.Empresa1 & 3.Empresa4 & 4.Empresa3 & 5.Empresa5 & 6.Empresa6 \\
\hline
\end{tabular}

\section{CONCLUSIONES}

En términos generales se puede concluir que las empresas objeto de la muestra, aunquesonempresasgrandes, bienes tructu radasy poseedoras degran descapitales en sus ac tivos tangibles, están aún en un proce so in cipien te enlo re feren te al registro delosprocesosdegestióndelconocimiento.

Lo an te riorpuede serco rroboradoporloilustradoenla Tabla5.Lasherramientas es tánor de na das allípor el gra do pro me dio de ob ten ción de res pues tas tras aplicarle elinstrumentoalasempresasdelamuestra.

\section{Tabla 5}

\begin{tabular}{|l|c|}
\hline \multicolumn{1}{|c|}{ Herramienta } & $\begin{array}{c}\text { Grado promedio de obten- } \\
\text { ción de respuestas en las } \\
\text { empresas de la muestra }\end{array}$ \\
\hline AprendizajeOrganizacional & $24.0 \%$ \\
\hline Documentación & $20.0 \%$ \\
\hline Terminología & $6.7 \%$ \\
\hline Normalización & $6.1 \%$ \\
\hline GestiónTecnológica & $0.0 \%$ \\
\hline \multicolumn{1}{|c|}{ Promedio } & $\mathbf{1 1 . 3 \%}$ \\
\hline
\end{tabular}

Como se observa en la tabla, el grado promedio de obtención de respuestas es muy bajo, $11.3 \%$. Este fenómeno po dría serex plica do portres fac to res. Un primer fac torsería quelas di ficul tades aso cia das alins trumen topodrían haberincididoen la cantidad de información obtenida. Un segundo factor es que las empresas de la mues trapue den es tarlle van do a cabo activida des rela ciona das conla ges tión del conocimiento,estructuradas deunamaneradiferentealaplanteadaporelins trumento. Un tercer fac tor se ría quelas em pre sas de la mues tra no tie nen re gis tros de sus ac tivi dadesrelacionadas con lages tión del conocimien to. A partirdela ex pe rien cia vivida en elde sa rrollo delpre sentees tu dio, nos in clinamospor ex plicarelfenómenocomo unamezcladelostres factores mencionados, conunaaltaincidencia deltercerfactor.

5 Munera y Franco. 
Lasempresasanalizadas noregistranefectivamentelosacontecimientosdeintercambio de conocimiento. De tal manera que, aunque dichos acontecimientos pueden exis tir, la au sencia de re gis tro o sis te ma ti za ción de ellosimpidees ta blecerdiagnósticos claros y precisos acerca del estado de la gestión del conocimiento en las empresasobjetodelestudio.

Elprocesodeintroducciónydesarrollodeactividadesrelacionadas conlagestión del conocimiento, como lo es la aplicación del instrumento desarrollado en el presentetrabajo,escos tosoycomplejo. Serequiere, además deempeñoy riguro sidaden eldesarrollodelproceso, elliderazgodelpersonaldirectivodelaempresa.

Elgra do de com plejidad delins tru men to de evalua ción se pue de conver tiren un obs tá culoparasuaplica ción. Valdríalapena formular diversosinstru men tos de eva luación con diferentes niveles de profundidad, para que éstos fueran aplicados de acuer do con el nivelde de sa rro llo delos pro ce sos de ges tión del co no cimientodelas empresas.

Este es tu diologra au men tarel gra do de fa mi lia ridad con el ma ne jo de la ges tión del co no cimien to en al gu nas em pre sas de servicios dela Ciu dad de Me dellín y da la posibilidadde establecer, posteriormente, investigaciones más rigurosassobre este fenómeno.

\section{BIBLIOGRAFÍA}

AGUADERO FERNÁNDEZ, Francisco. La soieđad de la infomadón / Francisco Aguadero Fernandez. - Madrid : Acento, 1997. - p. 16.

FLORES,Je sús, Lagestiónddconoaimientoenlasempresas [s. L. : s. n.], (2000)

INSTITUTO COLOMBIANO DE NORMAS TÉCNICAS. Normalización [documento electrónico]. - Bogotá : Icontec, 2003.

http: //www.icontec.org.co/normalizacion.asp/ [consulta mar. 24 2003]

MÚNERA TORRES, María Teresa. "Investigación sobre la incidencia de la ges tión del co no ci mien to en las em pre sas de servi cios de Me dellín", en Tendenias de Investigacón en agganizadón dd conoimiento = Trends in knowkedgeorganization reserch - Sala manca:UniversidaddeSala manca, c2003. P. 554. 


\section{InvestigaaónBiblictecoógia v. 17 N o. 35 julio/ diciembre de 2003}

MÚNERA TORRES, Ma ría Te re sa. Investigadónsobrelaindidendaddagestión dd conoimiento en las empresas deMeedlín entre 1995 y 2001. - Medellín : Universidad de Antioquia, EscuelaInteramericana de Bibliotecología, 2000. -10 p.

--, Franco, José Gre go rio. "La termi no lo gía y su re la ción con la ges tión del conocimiento", en 8o SimposiolberomericanodeTemindoǵa Cartagena de Indias : Riterm, 28 al 31 de octubre 2002.

--, Pa bón An gel, Ari log. Lagestióndd conodimientoysurelaciónconladbaumen tacón / María Teresa Múnera Torres y Arilog Regina Pabón Angel. Medellín. - Vol. 25, no. 2 (jul-dic 2002) ; p. 36

PICHT, Heribert, "Terminología para la empresa y la industria" / Heribert Picht. en TexersimposiolbercamericanadeTerminoloǵa, Riterm:Termi ndoǵayDesamdlo / Unión Latina. - Buenos Aires, 1994. - pp. 91-97. 